\title{
CALPUFF and AERMOD Dispersion Models for Estimating Odor Emissions from Industrial Complex Area Sources
}

\author{
Sang Jin Jeong* \\ Department of Environmental and Energy Systems Engineering, Kyonggi University, Suwon 442-760, Korea \\ *Corresponding author. Tel: +82-31-249-9734, E-mail: sjjung@kyonggi.ac.kr
}

\begin{abstract}
This study assesses the dispersion and emission rates of odor form industrial area source. CALPUFF and AERMOD Gaussian models were used for predicting downwind odor concentration and calculating odor emission rates. The studied region was Seobu industrial complex in Korea. Odor samples were collected five days over a year period in 2006. In-site meteorological data (wind direction and wind speed) were used to predict concentration. The BOOT statistical examination software was used to analyze the data. Comparison between the predicted and field sampled downwind concentration using BOOT analysis indicates that the CALPUFF model prediction is a little better than AERMOD prediction for average downwind odor concentrations. Predicted concentrations of AERMOD model have a little larger scatter than that of CALPUFF model. The results also show odor emission rates of Seobu industrial complex area were an order of 10 smaller than that of beef cattle feed lots.
\end{abstract}

Key words: CALPUFF model, AERMOD model, Odor dispersion, Area source, Emission rate, Industrial complex

\section{INTRODUCTION}

Population growth and housing needs have resulted in increasing numbers living within close proximity to these odor sources. And therefore the emission of odor from landfill sites and industrial process is a recurrent problem for operation and regulators, who have to deal with complaints from the public (Drew et al., 2007). Although it was found no significant association between odor perceptibility and potential for inducing health effects (Rosenkranz and Cunningham, 2003), adverse effect of odor is often classified as contaminants and is subject to regulation (Nicell, 2009).

The nuisance caused by the odor emitted from areal sources such as wastewater treatment plants, munici- pal refuse tips and beef cattle feedlots can be viewed to consist of a number of sequential processes: generation; release; transport; dispersion; and reception each of which is difficult to deal with in quantitative terms (Smith, 1995). Dispersion modeling uses mathematical equations, describing the atmosphere, dispersion and chemical and physical processes within the plume, to calculate concentrations at various locations (Holmes and Morawska, 2006).

To evaluate the nuisance, it is necessary to know downwind odor concentrations emitted from odor sources. Numerous gas dispersion models have been used to predict odor concentrations resulting from a known odor source dispersing into the atmosphere. Smith (1995) used a Gaussian model for estimating odor emissions from area sources. A fluctuating plume dispersion model (Mussino et al., 2001) was used for the prediction of odor-impact frequencies from continuous stationary sources. Sarkar et al. (2003) investigated odor emission of solid waste landfill site in north London using COMPLEX-1 software developed by the US-EPA. Sheridan et al. (2004) selected the ISCST3 model to determining the odor impact of intensive pig production units in Ireland. Wang et al. (2006) used CALPUFF and ISCST3 Gaussian dispersion modes to predict downwind odor concentration and back-calculating area sources odor emission rates of the commercial beef cattle feedlots. Drew et al. (2007) attempt to assess the appropriateness of using different averaging times to model the dispersion of odor from landfill site using the ADMS 3.1 air dispersion model.

Odorous gas emission from large confined industrial complex has been of increasing concern in Korea. This concern accentuates the need for additional study of odor mitigation and modeling. In this study, CALPUFF and AERMOD dispersion model were used to estimate odor emissions and predict odor concentrations from industrial complex area sources. The statistical procedures used to evaluate the model's performance are based on Chang and Hanna (2004) and the results from the statistical comparison between observed ground level concentrations of odor are presented. 


\section{MATERIALS AND METHODS}

\subsection{CALPUFF Dispersion Model}

As described in "A User's guide for the CALPUFF dispersion model" (Earth Tech, Inc., 2000), CALPUFF modeling system has three main components: CALMET, CALPUFF, and CALPOST. CALMET is a meteorological model that develops hourly wind and temperature fields on a 3-dimensional gridded modeling domain. CALPUFF is a transport and dispersion model that describes "puff" of material emitted from modeled sources, simulating dispersion and transformation processes along the way. CALPOST is used to process the files from CALPUFF, processing a summary of the simulation results in tabulated forms (Wang et al., 2006).

CALPUFF is non-steady-state Lagrangian Gaussian puff model. The basic equation for the contribution of a puff at the receptor is:

$$
\begin{aligned}
& \mathrm{C}=\frac{\mathrm{Q}}{\pi \sigma_{\mathrm{y}} \sigma_{\mathrm{z}}} \mathrm{g} \exp \left[-\frac{\mathrm{d}_{\mathrm{a}}^{2}}{2 \sigma_{\mathrm{x}}^{2}}\right] \exp \left[-\frac{\mathrm{d}_{\mathrm{c}}^{2}}{2 \sigma_{\mathrm{y}}^{2}}\right] \\
& \mathrm{g}=\frac{2}{\sqrt{2 \pi} \sigma_{\mathrm{z}}} \sum_{\mathrm{n}=-\infty}^{\infty} \exp \left[\frac{\left(\mathrm{H}_{\mathrm{e}}+2 \mathrm{nh}\right)^{2}}{2 \sigma_{\mathrm{z}}^{2}}\right]
\end{aligned}
$$

Where $\mathrm{C}$ is the ground level pollutant concentration (OU), Q is the product of odor strength in the puff and the puff volume $\left(\mathrm{OUm}^{3}\right), \sigma_{\mathrm{x}}$ is the standard deviation (m) of the Gaussian distribution in the along-wind direction, $\sigma_{\mathrm{y}}$ is the standard deviation (m) of crosswind direction, $\sigma_{z}$ is the standard deviation $(\mathrm{m})$ of the Gaussian distribution in the vertical direction, $d_{a}$ is the distance $(\mathrm{m})$ from the puff center to the receptor in the along-wind direction, $d_{c}$ is the distance $(m)$ from the puff center to the receptor in the cross-wind direction, $g$ is the vertical term $\left(\mathrm{m}^{-1}\right)$ of Gaussian equation, $\mathrm{H}_{\mathrm{e}}$ is the effective height (m) above ground of the puff center and $\mathrm{h}$ is the mixed-layer height $(\mathrm{m})$. Because AERMOD model is steady state plume model, ISC option of CALPUFF model (steady state option) was used in this study.

\subsection{AERMOD Dispersion Model}

AERMOD is steady-state plume model. The modeling system consists of one main program (AERMOD) and two pre-processors (AERMET and AERMAP). The major purpose of AERMET is to calculate boundary layer parameters for use by AERMOD. AERMAP is terrain pre-processor. In general, AERMOD models a plume as a combination of two limiting cases: a horizontal plume (terrain impacting) and a terrain following plume. Therefore, for all situations, the total concentration, at a receptor, is bounded by the concentra- tion predictions from these states. In flat terrain the two states are equivalent. By incorporating the concept of the dividing stream height, in elevated terrain, AERMOD's total concentration is calculated as a weighted sum of the concentration associated with these two limiting cases or plume states (US EPA, 2004). In AERMOD model the general concentration equation, which applies in stable or convective conditions is given by

$\mathrm{C}_{\mathrm{T}}\left\{\mathrm{x}_{\mathrm{r}}, \mathrm{y}_{\mathrm{r}}, \mathrm{z}_{\mathrm{r}}\right\}=\mathrm{f} \cdot \mathrm{C}_{\mathrm{c}, \mathrm{s}}\left\{\mathrm{x}_{\mathrm{r}}, \mathrm{y}_{\mathrm{r}}, \mathrm{z}_{\mathrm{r}}\right\}+(1-\mathrm{f}) \mathrm{C}_{\mathrm{c}, \mathrm{s}}\left\{\mathrm{x}_{\mathrm{r}}, \mathrm{y}_{\mathrm{r}}, \mathrm{z}_{\mathrm{p}}\right\}$

Where $\mathrm{C}_{\mathrm{T}}\left\{\mathrm{x}_{\mathrm{r}}, \mathrm{y}_{\mathrm{r}}, \mathrm{z}_{\mathrm{r}}\right\}$ is the total concentration, $\mathrm{C}_{\mathrm{c}, \mathrm{s}}$ $\left\{\mathrm{x}_{\mathrm{r}}, \mathrm{y}_{\mathrm{r}}, \mathrm{z}_{\mathrm{r}}\right\}$ is the contribution from the horizontal plume state (subscripts $\mathrm{c}$ and $\mathrm{s}$ refer to convective and stable condition, respectively), $\mathrm{C}_{\mathrm{c}, \mathrm{s}}\left\{\mathrm{x}_{\mathrm{r}}, \mathrm{y}_{\mathrm{r}}, \mathrm{z}_{\mathrm{p}}\right\}$ is the contribution from terrain-following state, $\mathrm{f}$ is the plume state weighting function, $\left\{\mathrm{x}_{\mathrm{r}}, \mathrm{y}_{\mathrm{r}}, \mathrm{z}_{\mathrm{r}}\right\}$ is the coordinate representation of a receptor (with $\mathrm{z}_{\mathrm{r}}$ defined relative to stack base elevation), $z_{p}=z_{r}-z_{t}$ is the height of a receptor above local ground level and $z_{t}$ is terrain height at a receptor.

\subsection{Back-calculating Odor Emission Rates}

The emission rates of industrial complex area source are estimated using measured concentrations in and downwind locations. For a given field downwind concentration measurement $\mathrm{C}_{2}\left(\mathrm{OUms}^{-1}\right.$ for area source $)$ the corresponding emission rate $\mathrm{Q}_{2}$ was determined using the following equation(Faulkner et al., 2007; Wang et al., 2006):

$$
\mathrm{Q}_{2}=\mathrm{Q}_{1} \times \frac{\mathrm{C}_{2}}{\mathrm{C}_{1}}
$$

Where $\mathrm{Q}_{1}$ is the model initial emission rate corresponding to initial modeled downwind concentration $\mathrm{C}_{1}\left(\mathrm{OUms}^{-1}\right.$ for area source $)$.

\section{4 Computational Domain and Ambient Odor Sampling}

Seobu industrial complex is the east of central area of Incheon city and has a total area of about 0.035 $\mathrm{km}^{2}$ (e.g. about $0.7 \mathrm{~km} \times 0.5 \mathrm{~km}$ ). It composed of various industry types such as coating, metal, wood, electronic components, automobile, waste, sewage, and plastic. There are 131 companies in Seobu industrial complex during 2006 (Kwack et al., 2008). In Fig. 1 , the computational region and measuring points of odor concentration and meteorology are given. As shown in Fig. 1, computational region was selected as $6 \mathrm{~km} \times 5 \mathrm{~km}$ in and around the Seobu industrial complex. The experimental procedures for the collection and analysis of odor samples has been described elsewhere (Kwack et al., 2008). Although the measure- 


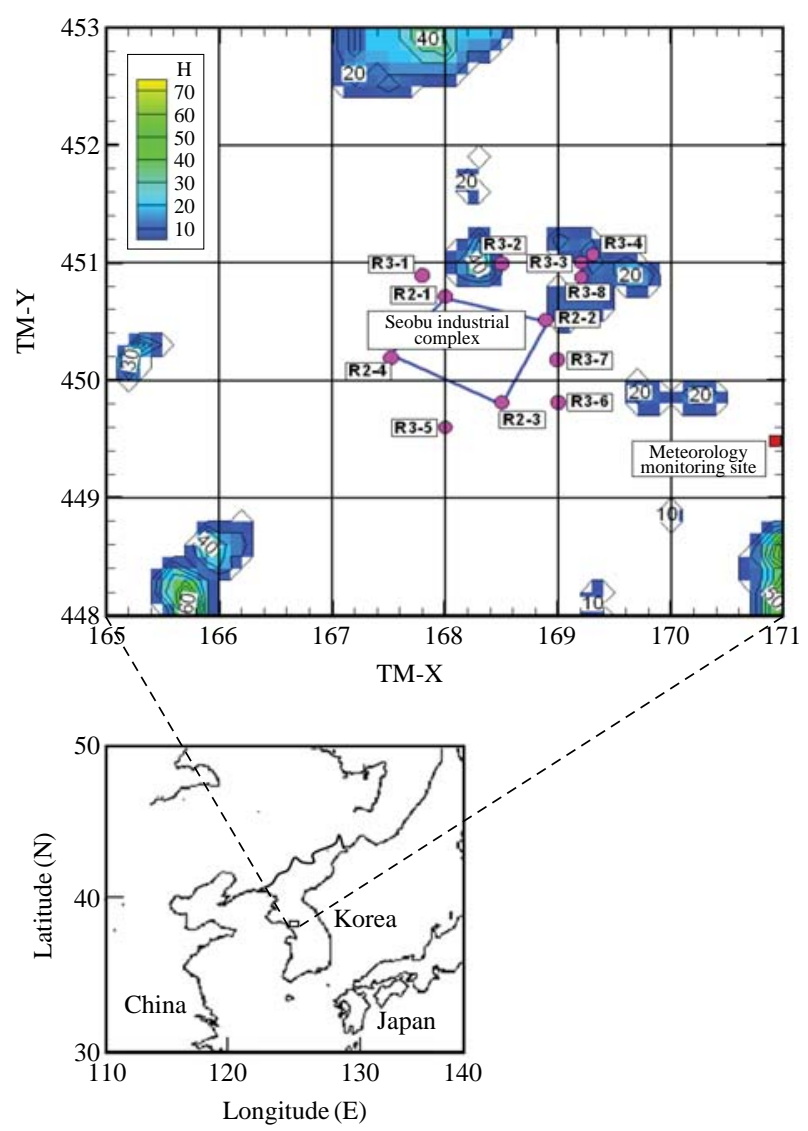

Fig. 1. Computational domain of Seobu industrial complex. ' $\mathrm{R}$ ' denotes receptor position.

ments were made to cover a total of 9 days, the use of these experimental data confined to four days in the present study. Because upwind and downwind sampling locations were determined abruptly, we choose 11 cases which had the same wind direction at the time of sampling: 17 April 2006 (case 1, 2, 3, and 4), 13 June 2006 (case 5), 7 August 2006 (case 6, 7), 10 August 2006 (case 8, 9, 10), and 6 December 2006 (case 11). Ambient odor samples were collected from three positions: four points in the middle of the source area (Because these points were within the industrial complex, we did not described in Fig. 1), four points of the border of the emission source area (e.g. R2-1 etc.), and eight points of receptor position (e.g. R3-1 etc.).

Odor samples were collected in 10-L Tedlar bags at a height $1 \mathrm{~m}$ above the ground surface. Meteorological data including near-surface measurement and upperair sounding were extracted from Incheon surface monitoring station (about $5 \mathrm{~km}$ away) and Osan upperair monitoring station (about $50 \mathrm{~km}$ away), respectively. In-site weather station meteorological data were also used to model downwind odor concentration at given emission rate.

\subsection{Evaluation of Dispersion Model Performance}

Hanna et al. (1993) suggested a set of quantitative statistical performance measure for evaluating models, and implemented the procedures in a software package called BOOT. The performance measures have been widely used in many studies and have been adopted as a common model evaluation framework for the European Initiative on "Harmonization within Atmospheric Dispersion Modeling for Regulatory Purposes" (Chang and Hanna, 2004). In order to evaluate the predictions of model with observations, Hanna et al. (1993) recommended the use of the following statistical performance measures, which include the fractional bias (FB), the geometric mean bias (MG), the normalized mean square error (NMSE), the geometric variance (VG), the correlation coefficient $(\mathrm{R})$, and the fraction of predictions within a factor of two observations (FAC2) is given by

$$
\begin{aligned}
& \mathrm{FB}=\frac{\overline{\mathrm{C}_{\mathrm{o}}}-\overline{\mathrm{C}_{\mathrm{p}}}}{0.5\left(\overline{\mathrm{C}_{\mathrm{o}}}-\overline{\mathrm{C}_{\mathrm{p}}}\right)} \\
& \mathrm{MG}=\exp \left(\overline{\ln \mathrm{C}_{\mathrm{o}}}-\overline{\ln \mathrm{C}_{\mathrm{p}}}\right) \\
& \mathrm{NMSE}=\frac{\overline{\left(\mathrm{C}_{\mathrm{o}}-\mathrm{C}_{\mathrm{p}}\right)^{2}}}{\overline{\mathrm{C}_{\mathrm{o}}} \overline{\mathrm{C}_{\mathrm{p}}}} \\
& \mathrm{VG}=\exp \left[\overline{\left(\ln \mathrm{C}_{\mathrm{o}}-\ln \mathrm{C}_{\mathrm{p}}\right)^{2}}\right]
\end{aligned}
$$

$\mathrm{FAC} 2=$ fraction of data that satisfy

$0.5 \leq \frac{\mathrm{C}_{\mathrm{p}}}{\mathrm{C}_{\mathrm{o}}} \leq 2.0$

Where $\mathrm{C}_{\mathrm{p}}$ is model prediction, $\mathrm{C}_{\mathrm{o}}$ is observation. Over bar denotes average over the data set.

A perfect model would have MG, $\mathrm{VG}$, and $\mathrm{FAC} 2=$ 1.0; and FB and NMSE $=0.0$. Because of the influence of random atmospheric processes, there is no such thing as a perfect model in air quality modeling. Note that since FB and MG measure only the systematic bias of a model, it is possible for a model to have predictions completely out of phase of observations and still have $\mathrm{FB}=0.0$ or $\mathrm{MG}=1.0$ because of canceling errors. FB and MG can be interoperated by the following equations:

$$
\begin{aligned}
& \frac{\overline{\mathrm{C}_{\mathrm{p}}}}{\overline{\mathrm{C}_{\mathrm{o}}}}=\frac{1-0.5 \cdot \mathrm{FB}}{1+0.5 \cdot \mathrm{FB}} \\
& \frac{\left\langle\mathrm{C}_{\mathrm{p}}\right\rangle}{\left\langle\mathrm{C}_{\mathrm{o}}\right\rangle}=\frac{1}{\mathrm{MG}}
\end{aligned}
$$


Table 1. Meteorological condition and calculated emission rates.

\begin{tabular}{|c|c|c|c|c|c|c|}
\hline Case No. & $\begin{array}{l}\text { Receptor } \\
\text { No. }\end{array}$ & Measuring time & $\begin{array}{l}\text { Wind speed } \\
\quad\left(\mathrm{ms}^{-1}\right)\end{array}$ & $\begin{array}{l}\text { Stability } \\
\text { condition }\end{array}$ & $\begin{array}{l}\text { CALPUFF emission } \\
\text { rates }\left(\mathrm{OUm}^{2} / \mathrm{s}\right)\end{array}$ & $\begin{array}{l}\text { AERMOD emission } \\
\text { rates }\left(\mathrm{OUm}^{2} / \mathrm{s}\right)\end{array}$ \\
\hline 1 & R 2-4 & 03/17 13:00-13:10 & 2.0 & $\mathrm{~B}$ & 0.279 & 0.437 \\
\hline 2 & R 2-2 & 03/17 14:58-15:08 & 2.0 & $\mathrm{~B}$ & 0.279 & 0.437 \\
\hline 3 & R 3-6 & $03 / 17$ 16:45-16:55 & 1.65 & $\mathrm{C}$ & 0.279 & 0.437 \\
\hline 4 & R 3-7 & 03/17 17:00-17:10 & 1.65 & $\mathrm{C}$ & 0.279 & 0.437 \\
\hline 5 & R 2-1 & $06 / 13$ 11:35-11:50 & 2.5 & $\mathrm{~B}$ & 0.142 & 0.494 \\
\hline 6 & R 2-4 & 08/07 20:05-20:20 & 2.0 & $\mathrm{D}$ & 0.128 & 0.029 \\
\hline 7 & R 3-5 & 08/07 19:40-19:55 & 2.0 & $\mathrm{C}$ & 0.128 & 0.029 \\
\hline 8 & R 2-2 & 08/10 19:50-20:05 & 1.67 & $\mathrm{C}$ & 0.176 & 0.026 \\
\hline 9 & R 3-6 & 08/10 21:55-22:10 & 1.67 & $\mathrm{D}$ & 0.176 & 0.026 \\
\hline 10 & R 3-7 & 08/10 21:35-21:50 & 1.67 & $\mathrm{D}$ & 0.176 & 0.026 \\
\hline 11 & R 2-1 & $12 / 06$ 21:00-21:20 & 2.0 & $\mathrm{E}$ & 0.164 & 0.057 \\
\hline Average & & & & & 0.201 & 0.208 \\
\hline
\end{tabular}

Where $\langle\mathrm{C}\rangle$ refers to the geometric mean of the dataset.

Chang and Hanna (2004), after statistical examination of many dispersion datasets, have concluded that for 'research grade' field experiments (such as MUST), a range of metric values to indicate 'acceptable model performance' is as follows: $-0.3<\mathrm{FB}<0.3,0.7<$ $\mathrm{MG}<1.3, \mathrm{NMSE}<4.0, \mathrm{VG}<1.6$, and $0.5<\mathrm{FAC}<$ 2.0 (Donnelly et al., 2007).

\section{RESULTS AND DISCUSSION}

Table 1 lists meteorological conditions and calculated odor emission rates of eleven episode cases. Observed wind speeds were ranged from $1.65 \mathrm{~ms}^{-1}$ to $2.0 \mathrm{~ms}^{-1}$ $\left(1.89 \mathrm{~ms}^{-1}\right.$ in average). Stability conditions were between $\mathrm{B}$ to $\mathrm{C}$ for the day time and $\mathrm{D}$ to $\mathrm{E}$ at the night time. Calculated average emission rate was 0.201 $\mathrm{OU} \mathrm{ms}^{-1}$ (ranged from 0.128 to $0.279 \mathrm{OU} \mathrm{ms}^{-1}$ ) for CALPUFF model and was $0.208 \mathrm{OU} \mathrm{ms}^{-1}$ (ranged from 0.026 to $0.494 \mathrm{OU} \mathrm{ms}^{-1}$ ) for AERMOD model. These average emission rates were an order of 10 smaller than that (1.19 OU ms $\left.{ }^{-1}\right)$ of Wang et al.'s (2006) for beef cattle feedlots. The reason why Wang et al.'s emission rate was different from our result was partly due to the different source sampling method. We calculated average emission rates using sampled ambient air, but Wang et al. evaluated average emission rates using flux chamber.

According to Faulkner et al. (2007), when locating samplers used to calculate the flux of emission from a GLAS (Ground Level Area Source), uncertainty associated with calculations. The closer the sampler to the source, the less influence outside sources will have. Samplers should be placed along the LMC (Line of maximum concentration) or within the source to eliminate modeling uncertainty resulting from uncertainty in the dispersion parameters near the edge of a plume.
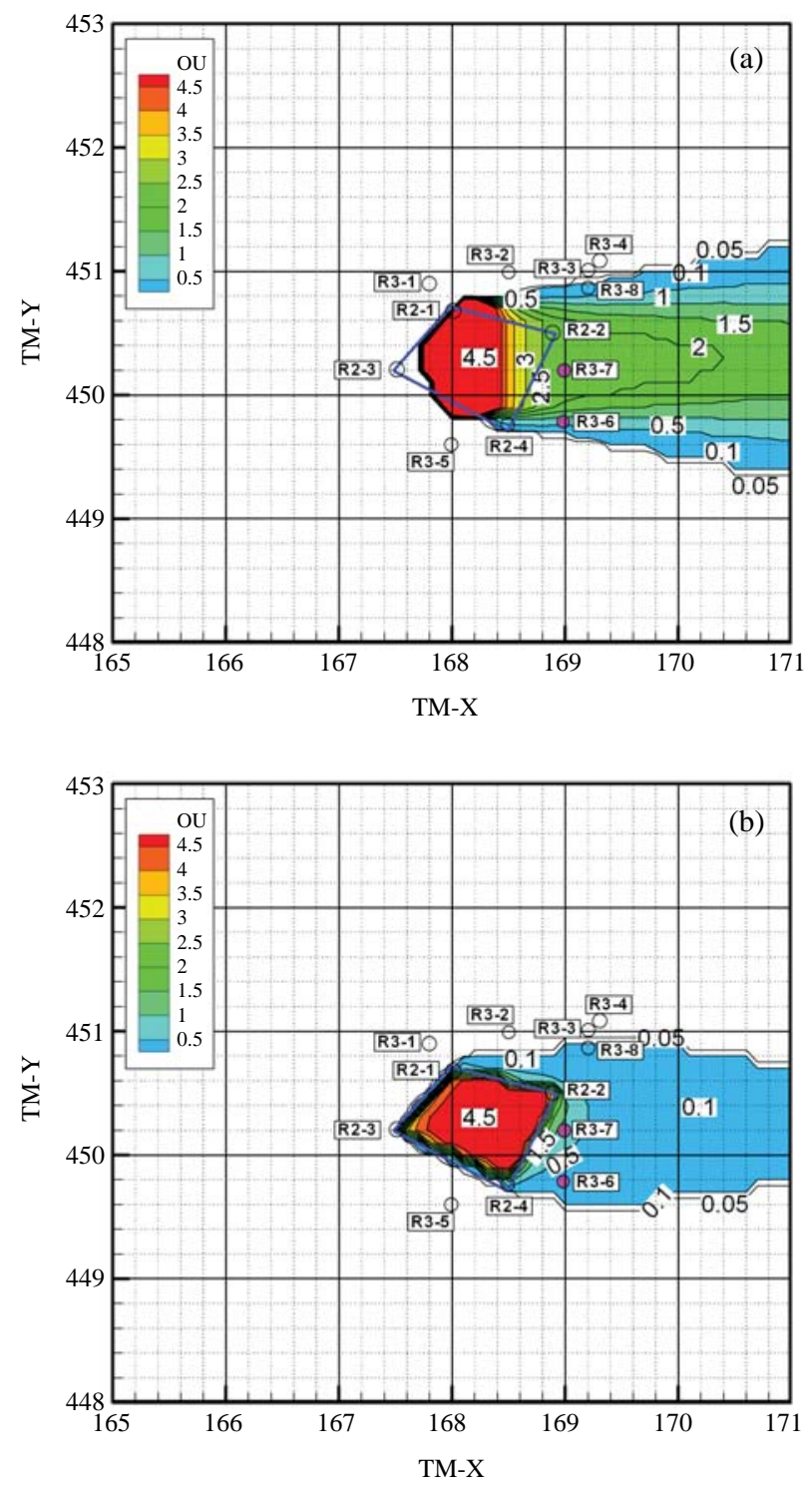

Fig. 2. Odor Unit contour of selected day (Case 3, 4: Time: 2006-03-17-17:00). (a) CALPUFF, (b) AERMOD 
The father the sampler is from the source, the more likely interference from uncertainty near plume edge will occur.

Fig. 2 to 4 shows modeling results of 5 episode cases. As shown in these figures, all of the sampler positions (filled circle) are located within LMC to eliminate modeling uncertainty as mentioned by Faulkner et al. (2007). Fig. 2 shows the calculated results of case 3 and 4 . In these cases, wind speed was $1.65 \mathrm{~ms}^{-1}$, wind direction was from west to east, and stability class was C. As expected, both models fairly good simulate odor dispersion from the west to the east but downwind odor concentration of CALPUFF model is larger than that of AERMOD model. The case of odor movement
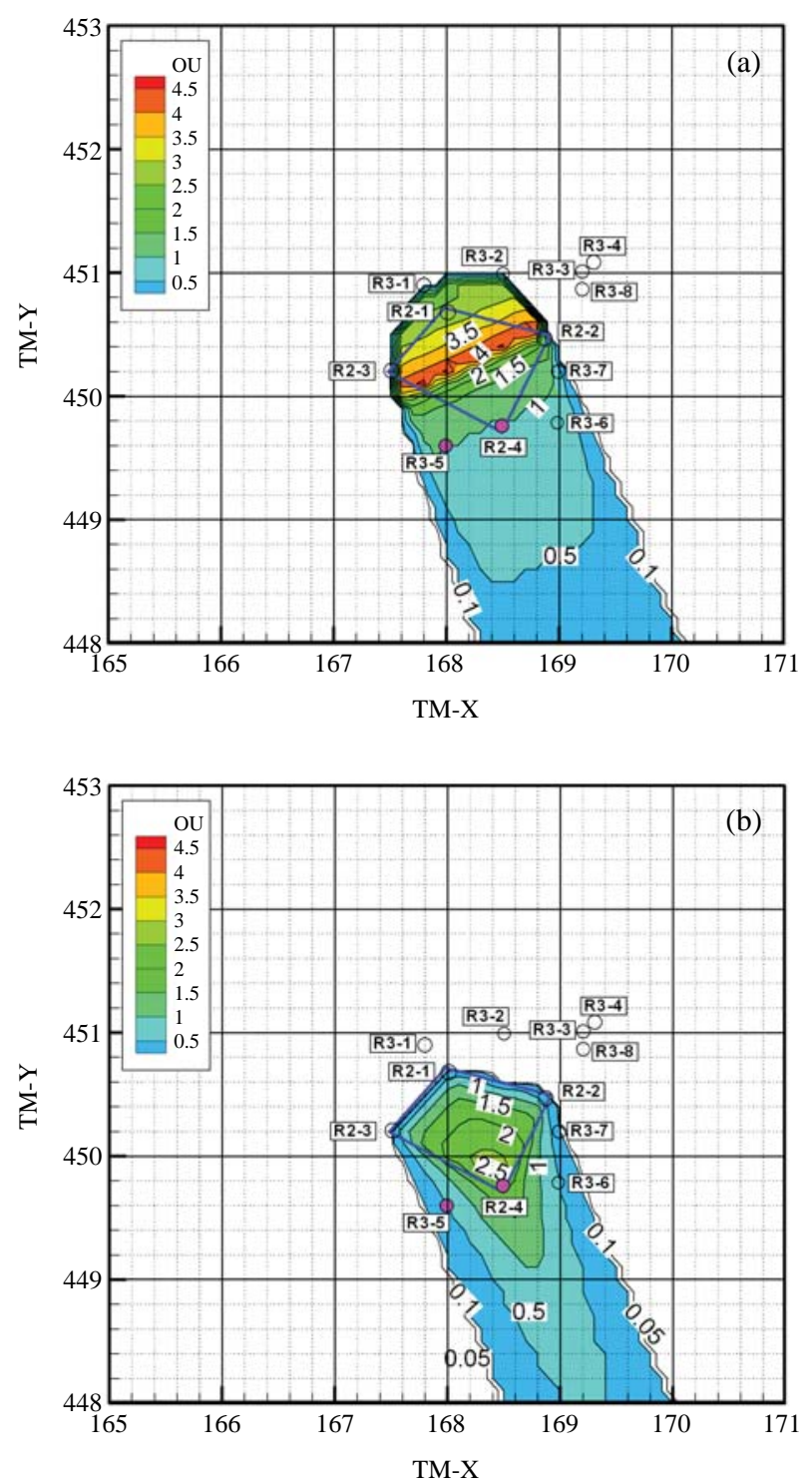

Fig. 3. Odor Unit contour of selected day (Case 6, 7: Time: 2006-08-07-20:00). (a) CALPUFF, (b) AERMOD from the north east to the south west (case 6 and 7) were shown in Fig. 3. Overall, downwind concentration distribution of these cases was not largely different both model. Fig. 4 shows the calculated results of case 11 . In this night time case, mean wind speed was $2.0 \mathrm{~ms}^{-1}$, stability class was E, and odor moved from the south east to the north west. Like other cases, both model results show similar odor contour pattern.

To check the model's tendency to over or under-predict concentrations, comparison between observation concentrations and model prediction concentrations are shown in Fig. 5. Because all measured concentration points are located within LMC, predicted concentrations are reasonable agree to the observed concen-
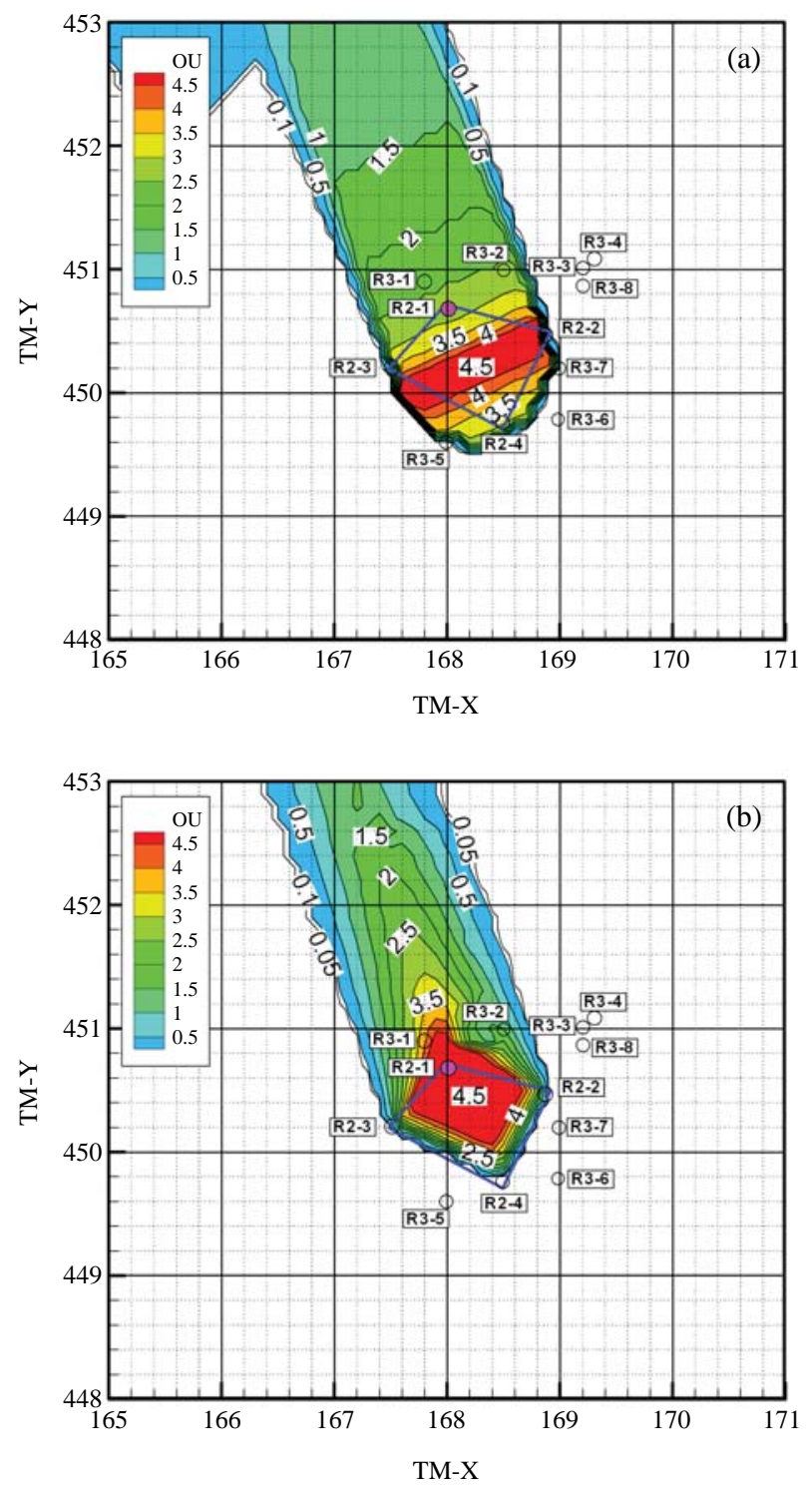

Fig. 4. Odor Unit contour of selected day (case 11, Time: 2006-12-06-21:00). (a) CALPUFF, (b) AERMOD 
Table 2. Model performance evaluations.

\begin{tabular}{|c|c|c|c|c|}
\hline Metrics & Definition & CALPUFF & AERMOD & Acceptable range \\
\hline FB & $\frac{\left(\overline{\mathrm{C}_{\mathrm{o}}}-\overline{\mathrm{C}_{\mathrm{p}}}\right)}{0.5\left(\overline{\mathrm{C}_{\mathrm{o}}}-\overline{\mathrm{C}_{\mathrm{p}}}\right)}$ & 0.24 & -0.019 & $-0.3<\mathrm{FB}<0.3$ \\
\hline MG & $\exp \left(\overline{\operatorname{lnC_{o}}}-\overline{\ln C_{p}}\right)$ & 1.42 & 1.392 & $0.7<\mathrm{MG}<1.3$ \\
\hline NMSE & $\frac{\overline{\left(\mathrm{C}_{\mathrm{o}}-\mathrm{C}_{\mathrm{p}}\right)^{2}}}{\overline{\mathrm{C}_{\mathrm{o}} \mathrm{C}_{\mathrm{p}}}}$ & 0.27 & 0.499 & $\mathrm{NMSE}<4$ \\
\hline VG & $\exp \left[\overline{\left(\ln C_{0}-\ln C_{p}\right)^{2}}\right]$ & 1.44 & 2.461 & $\mathrm{VG}<1.6$ \\
\hline FAC2 & $\overline{\mathrm{C}_{\mathrm{o}}} / \overline{\mathrm{C}_{\mathrm{p}}}$ & 0.87 & 1.019 & $0.5 \leq \mathrm{FAC} 2 \leq 2.0$ \\
\hline
\end{tabular}

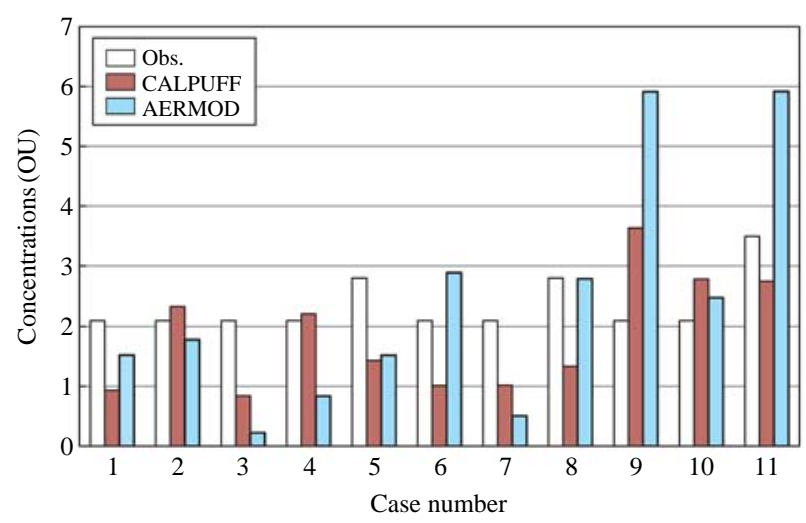

Fig. 5. Comparison between predicted and field observation concentrations.

trations for both models. But AERMOD model results have a little larger scatter than that of CALPUFF model results. To investigate the model's tendency to over or under predict concentrations, BOOT statistics of the point to point comparison was made. Table 2 summarizes model performance evaluations. FB shows the slight mean over prediction of the AERMOD mo$\operatorname{del}\left(\overline{\mathrm{C}_{\mathrm{o}}} / \overline{\mathrm{C}_{\mathrm{p}}}=1.109\right)$ and under prediction of the CALPUFF model $\left(\overline{\mathrm{C}_{\mathrm{o}}} / \overline{\mathrm{C}_{\mathrm{p}}}=0.87\right)$. NMSE $=1.0$ implies that the root-mean-square-error is equal to the mean. As NMSE becomes much larger than 1.0, it can be inferred that the distribution is not normal but is closer to log-normal (Chang and Hanna, 2004). So the small NMSE of 0.27 (CALPUFF) and 0.449 (AERMOD) show the data distributions of CALPUFF and AERMOD are normal.

\section{CONCLUSIONS}

The dispersion and emission rates of odor form industrial area source were evaluated using CALPUFF and AERMOD dispersion model. The studied region was
Seobu industrial complex in Korea. Odor samples were collected five days over a year period in 2006. In-site meteorological data (wind direction and wind speed) were used to predict concentration. The BOOT statistical examination software was used to analyze the data.

The results show calculated emission rates of both models are an order of 10 smaller than that $1.19 \mathrm{OU}$ $\mathrm{ms}^{-1}$ ) of Wang et al.'s (2006) for beef cattle feedlots. When locating the sampler within LMC, predicted concentration is reasonable agree to the observed concentrations for both models. However, predicted concentrations of AERMOD model have a little larger scatter than that of CALPUFF model. FB shows the slight mean over prediction of the AERMOD model $\left(\overline{\mathrm{C}_{\mathrm{o}}} / \overline{\mathrm{C}_{\mathrm{p}}}=1.109\right)$ and under prediction of the CALPUFF model $\left(\overline{\mathrm{C}_{\mathrm{o}}} / \overline{\mathrm{C}_{\mathrm{p}}}=0.87\right)$. The small NMSE of 0.27 (CALPUFF) and 0.449 (AERMOD) show the data distributions of CALPUFF and AERMOD are normal.

\section{REFERENCES}

Chang, J.C., Hanna, S.R. (2004) Air quality model performance evaluation. Meteorology and Atmospheric Physics 87, 167-196.

Donnelly, R.P., Lyons, T.J., Flassak, T. (2007) Evaluation of results of a numerical simulation of dispersion in an idealized urban area for emergency response modelling. Atmospheric Environment 43, 4416-4423.

Drew, G.H., Smith, R., Gerard, V., Burge, C., Lowe, M., Kinnersley, R., Sneath, R., Longhurst, P.J. (2007) Appropriateness of selecting different averaging times for modelling chronic and acute exposure to environmental odours. Atmospheric Environment 41, 28702880.

Earth Tech Inc. (2000) A user's guide for the CALPUFF dispersion model version 5, Concord MA.

Faulkner, W.B., Lange, J.M., Powell, J.J., Shaw, B.W., Parnell, C.B. (2007) Sampler placement to determine emission factors from ground level area sources. Atmo- 
spheric Environment 41, 7622-7678.

Hanna, S.R., Chang, J.C., Strimaitis, D.G. (1993) Hazardous gas model evaluation with field observations. Atmospheric Environment 27A, 2265-2285.

Holmes, N.S., Morawska, L. (2006) A review of dispersion modeling and its application to the dispersion particles: An overview of different dispersion models available. Atmospheric Environment 40, 5902-5928.

Kwack, W.S., Chu, W.J., Lim, J.S., Kim, K.M., Jun, N.S., Lee, J.H., Lee, M.J., Hyun, J.Y., Bang, K.I. (2008) The study of the actual state of odor managing zones in Incheon metropolitan city. Korean Journal of Odor Research and Engineering 6(2), 106-155 (in Korean).

Mussino, P., Gnyp, A.W., Henshaw, P.F. (2001) A fluctuating plume model dispersion model for the prediction of odour-impact frequencies from continuous stationary sources. Atmospheric Environment 35, 2955-2962.

Nicell, J.A. (2009) Assessment and regulation of odor impacts. Atmospheric Environment 43, 196-206.

Rosenkrank, H.S., Cunningham, A.R. (2003) Environmental Odors and health hazards. The Science of the Total
Environment 313, 15-24.

Sarkar, U., Hobbs, S.E., Longhurst, P. (2003) Dispersion odour: a case study with a municipal solid waste landfill site in North London, United Kingdom. Journal of Environmental Management 68, 153-160.

Sheridan, B.A., Hayes, E.T., Curran, T.P., Dodd, V.A., (2004) A dispersion modeling approach to determining the odour impact of intensive pig production units in Ireland. Bioresources Technology 91, 145-152.

Smith, R.J. (1995) A Gaussian model for estimating odour emissions from area sources. Mathematical Computer Modelling 21(9), 23-29.

US EPA (2004) AERMOD: description of model formulation.

Wang, L., Parker, D.B., Parnell, C.B., Lacey, E.E., Shaw, B.W. (2006) Comparison of CALPUFF and ISCST3 models for predicting downwind odor and source emission rates. Atmospheric Environment 40, 4663-4669.

(Received 27 July 2010, accepted 2 December 2010) 